\title{
Female Breast Size Attractiveness for Men as a Function of Sociosexual Orientation (Restricted vs. Unrestricted)
}

\author{
Agnieszka M. Zelazniewicz $\cdot$ Boguslaw Pawlowski
}

Published online: 6 October 2011

(C) The Author(s) 2011. This article is published with open access at Springerlink.com

\begin{abstract}
Mate preferences are context-dependent and may vary with different ecological conditions and raters. The present study investigated whether sociosexual orientation influenced men's rating of attractiveness of female breast size. Participants $(N=128)$ rated female breast attractiveness as a function of size (five levels) and viewing angles (front view, oblique view, and side view). Men were divided into two groups (restricted and unrestricted), based on their responses to the Revised Sociosexual Orientation Inventory (SOI-R). As predicted, men with higher SOI-R scores (unrestricted) generally gave higher ratings than did men who scored lower on the SOI-R (restricted), but the difference was significant only at larger breast sizes. We also found that medium to large sizes were rated as the most attractive by both male groups and that viewing angle changed rating of female attractiveness and breast presented in oblique view were rated generally higher than in side view. The results of the study indicate that sociosexuality influences male perception of female breast attractiveness and confirm that accentuation of female-specific physical traits produces a stronger response in unrestricted than in restricted men.
\end{abstract}

Keywords Sociosexuality - Breast attractiveness . Breast size $\cdot$ Mate preferences - Attraction perception . Mating strategy

A. M. Zelazniewicz $(\bowtie) \cdot$ B. Pawlowski

Department of Anthropology, University of Wroclaw,

Kuznicza 35, 50-138 Wroclaw, Poland

e-mail: a.zelazniewicz@antropo.uni.wroc.pl

A. M. Zelazniewicz

Institute of Anthropology, Polish Academy of Sciences,

Wroclaw, Poland

\section{Introduction}

Attractiveness is judged by means of adaptive psychological mechanisms that have evolved to identify prospective mates who will increase reproductive success above the level expected in random mating (Buss \& Schmitt, 1993). Men are attracted to a number of physical characteristics in women, including youth cues, face shape, symmetry, waist-to-hip ratio (WHR), distribution of fat reserves, and other secondary sexual traits (Barber, 1995; Buss, 1989; Singh, 1993, 1995). Most of these visual cues have been recognized as markers of female fertility and good genes (Barber, 1995; Thornhill \& Gangestad, 1999) and correlate with health or fertility, as reflected by sex hormones level (e.g., Henderson \& Anglin, 2003; Jasienska, Lipson, Ellison, Thune, \& Ziomkiewicz, 2006; Scheib, Gangestad, \& Thornhill, 1999; Shackelford \& Larsen, 1999; Thornhill \& Grammer, 1999).

Female breasts are one of the secondary sexual traits that attract male attention and influence male judgments of attractiveness. Furnham and Swami (2007) showed that attractiveness ratings were even more strongly influenced by breast size than by buttock size (and hence WHR) when the female figure was presented in side view. Several characteristics may affect breast attractiveness, such as shape, asymmetry (Manning, Scutt, Whitehouse, \& Leinster, 1997), areola size and pigmentation (Dixson et al., 2010), but size is one of the most visible and possibly most "eye-catching," especially in cultures where clothing conceals breast shape. This appears to have been confirmed by Lynn (2009), who showed experimentally, for an American sample, that breast size matters more than breast shape in attractiveness rating.

As breasts' morphology changes with age and reproductive status, it is possible that those changes may affect female attractiveness and that different aspects of breast morphology may convey different signals to a potential mate (Symons, 1979). Breast shape, areola size, and color may provide men with a 
signal of women's age (Dixson et al., 2010) whereas size, as it increases with age and correlates with estrogen level, may be related both to age and fecundity (Jasienska, Ziomkiewicz, Ellison, Lipson, \& Thune, 2004). Previous research suggested that men across cultures may have a profound preference toward female morphology that signals nulliparity (Jones, 1996); therefore, if breast size is a strong cue of female age and as it increases after pregnancy, men should prefer breasts of smaller size. Most of the previous research, however, has shown that greater attractiveness ratings are associated with larger (Furnham, Dias, \& McClelland, 1998; Lynn, 2009; Singh \& Young, 1995) or average (Horvath, 1981; Tantleff-Dunn, 2002) female breast size. Some studies, however, failed to find any influence of breast size on attractiveness (Furnham, Swami, \& Shah, 2006) or have found preference for smaller breasts when presented in side view (Furnham \& Swami, 2007). Cross-cultural studies showed that men from New Zealand, Papua New Guinea, and Samoa, despite the difference in preference for areola color, equally prefer medium and large breast sizes over small ones (Dixson et al., 2010).

One explanation for these contradictory findings is that human mate preferences are context-dependent, influenced by different socioecological factors (Anderson, Crawford, Nadeau, \& Lindberg, 1992). Judgments of potential mate value can vary with ecological conditions (Swami \& Tovee, 2005; Westman \& Marlowe, 1999). For instance, men in developing societies and working class backgrounds have a preference for plumper women (Anderson et al., 1992). Judgments of potential mate value can also vary with the rater's characteristics, like attractiveness (Brase \& Walker, 2004), age or height (Pawlowski \& Jasienska, 2008; Waynforth \& Dunbar, 1995) or self-perceived value (Jones et al., 2005; Little, Burt, Penton-Voak, \& Perret, 2001) and markedly in relation to the rater's sexual strategy (Buss, 1989; Buss \& Schmitt, 1993; Gangestad \& Simpson, 2000; Provost, Troje, \& Quinsey, 2008; Swami, Miller, Furnham, Penke, \& Tovee, 2008).

Human sexual strategies are integrated sets of adaptations that drive reproductive effort in the direction of higher fitness. Fitness is notably influenced by a mate's genetic quality, by the capability to invest in offspring, and by female sexual exclusivity if the male contributes substantially to raising his offspring. Because all three criteria are probably difficult to meet in a single mate, individuals tend to focus on one of them, according to their sexual strategy (Simpson \& Gangestad, 1992). Men with a short-term mating strategy tend to pursue temporary, low-commitment sexual relationships with multiple partners. They should thus be strongly interested in cues that signal, in a prospective mate, fertility and health, but also willing to engage in short-term mating. By contrast, men with a long-term mating strategy tend to seek durable, high-investment relationships. They value not only reproductive potential and physical attractiveness but also non-physical traits, like interpersonal responsiveness, loyalty, chastity, commitment, and parental skills (Buss \& Schmitt,
1993; Simpson \& Gangestad, 1992). Sexual strategy may be reflected in sociosexuality, which is defined as a willingness to engage in sex without commitment. To measure this factor, Simpson and Gangestad (1991) used a short, self-report questionnaire, the Sociosexual Orientation Inventory (SOI). Individuals who scored low on SOI, and thus pursue a long-term mating strategy, were described as sociosexually restricted. Those who scored high, and thus pursue a short-term mating strategy, were described as sociosexually unrestricted.

Previous research reported that sexually unrestricted men, in comparison to sexually restricted men, valued physically attractive females more highly (Simpson \& Gangestad, 1992) and show greater sensitivity to female facial cues (Sacco, Hugenberg, \& Sefeck, 2009). They likewise give females with low WHR and low BMI a higher attractiveness rating (Swami, Jones, Einon, \& Furnham, 2009). Both traits are known to be highly attractive and related to female fertility (e.g., Singh, 1993; Tovee, Maisey, Emery, \& Cornelissen, 1999). Li and Kenrick (2006) showed that men prioritized physical attractiveness even more for short -term than for long-term mates. As reproductive gains from short-term mating would be largely eliminated if a female was not fertile, it is possible that ancestral men may have had an adaptive need to identify and pursue short-term partners who were healthy and fertile (Symons, 1979). Instead, individuals seem to compromise on physical attractiveness when seeking a long-term partner and emphasize interpersonal and emotional responsiveness (Kenrick, Sadalla, Groth, \& Trost, 1990; Regan, 1998) and tend to evaluate women's attractiveness more conservatively (Brase \& Walker, 2004).

In this study, we predicted, that male sociosexual orientation may also influence ratings of female breast attractiveness as a function of size. By studying individual differences in male preference for breast size as a function of male sexual strategy, we may better understand the contribution of female breasts size to sexual signaling and their role in the rating of female attractiveness (Furnham \& Swami, 2007). We predicted that, if large breasts are more attractive than small ones, and convey information on women's fertility, they should receive the highest ratings for both restricted and unrestricted men, with the highest ratings coming from the unrestricted ones, similar to difference in WHR attractiveness rating found by Swami et al. (2008).

\section{Method}

\section{Participants}

We recruited 128 heterosexual men from Wroclaw University of Technology, from Wroclaw University, from sports clubs in Wroclaw, and through the Polish social networking webpage www.nasza-klasa.pl. All men agreed to participate in the study. The mean age of participants was 23.42 years $(S D=2.45)$ with an age range of 19-29. To check whether attractiveness rating 
and SOI-R scores differed in relation to the way the data were collected, we compared men who completed the web-based survey $(N=48)$ with those who completed it on paper $(N=80)$. We found no significant difference between the two groups both in breast attractiveness ratings and in SOI-R scores $p>.10$. Therefore, in all further analyses, the two sets of scores were combined.

\section{Measures}

The survey was anonymous and had questions on demographics, sexual orientation, relationship status, height, and weight. All participants completed the SOI-R; Penke \& Asendorpf, 2008) and assessed attractiveness on a 9- point scale, where $1=$ very unattractive and $9=$ very attractive of female breasts as a function of size (5 levels) from three different angles (front view, oblique view, and side view; see Fig. 1). All participants assessed all 15 photographs of female breasts.

The SOI-R provides the participant's overall sociosexual orientation, which is based on three components: past sociosexual behavior (e.g., "With how many different partners have you had sex within the past 12 months?" or "With how many different partners have you had sexual intercourse on one and only one occasion?"), attitudes toward uncommitted sex (e.g., "Sex without love is ok" or "I can imagine myself being comfortable and enjoying 'casual' sex with different partners"); and desires (e.g., "How often do you have fantasies about having sex with someone you are not in a committed romantic relationship with?") (Penke \& Asendorpf, 2008). The SOI-R consists of 9 items ( 3 items per component). Responses were scored on a 9 point scale and summed to a total SOI-R score ranging from 9 to 81. A low score means restricted sociosexual orientation and a high score unrestricted sociosexual orientation. Because there was no difference in statistical results from all three facets, we focused on the overall sociosexual orientation.

\section{Procedure}

We used photographs of female breasts before (B size) and after surgical enlargement (D size). In comparison with line drawings, photographs allow for more authentic rating of perception of attractiveness (Swami et al., 2008; Tovee \& Cornelissen, 2001). Breasts were enlarged from 70B to 70D, without any additional plastic corrections that would change breast shape, nipple or bust position on the chest and possibly influence the attractiveness rating. Changes in shape of breasts were deliberately excluded to avoid potential influence of this trait. To exclude any potential influence of waist circumference on attractiveness rating, upper torso was shown from the neckline to the lower rib. This also helped to avoid exaggeration effects, where graphically enlarged breasts look unnatural and disproportionate on the unchanged female figure (Lynn, 2009). All photographs were black and white.
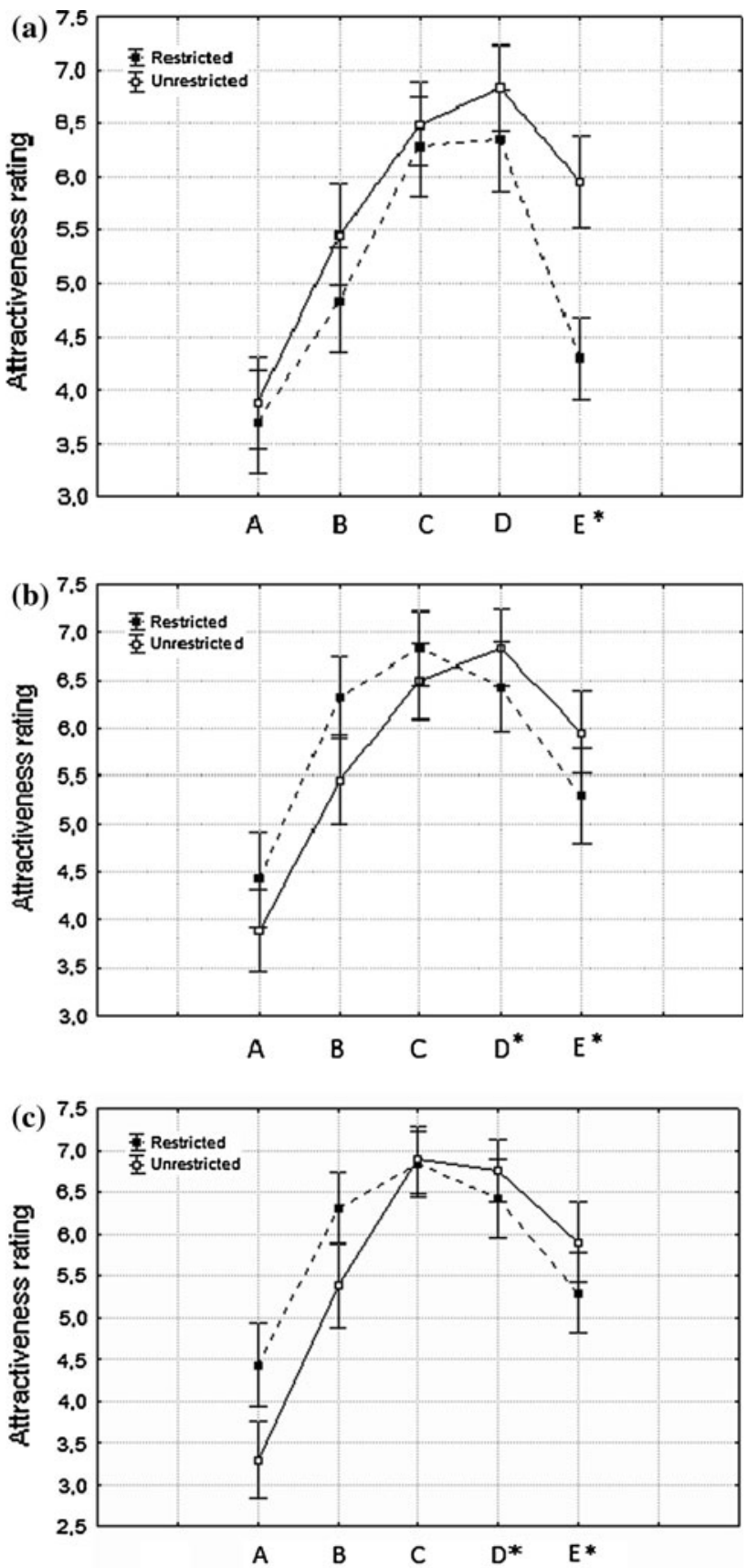

Fig. 1 Mean attractiveness ratings $(1=$ low, $9=$ high $)$ as a function of breast size and for restricted and unrestricted. a front view, $\mathbf{b}$ oblique view, and $\mathbf{c}$ side view. ${ }^{*} p<.001$

The five grades of the breast size scale were obtained by modifying the photographs with the Adobe Photoshop 7.0 program, without any changes to the original photographs for sizes $B$ and $D$. The A size was obtained by decreasing the $\mathrm{B}$ size, $\mathrm{C}$ by decreasing $\mathrm{D}$, and $\mathrm{E}$ by increasing $\mathrm{D}$. The photographs were presented in random order on three pages. Each page had five photographs of given profile.

To test interactions, analysis of variance for repeated measures was performed, with each breast size and profile and 
SOI-R of participant as a factor. The analysis used a crossed design to analyze the impact of SOI-R (2 levels), the size of the breast in the image (5 levels), and the profile (3 levels). Participants were instructed to make this judgment independently for each image and so the data were considered as independent as practically possible. All the analyses were carried out with SPSS 17.0 for Windows. All effects reported as significant were $p<.05$ with Bonferroni correction.

\section{Results}

\section{Sociosexual Orientation}

Since SOI-R scores were positively skewed $(M=31.67, S D=$ 14.06), we split the participants into those who scored below the mean score for the whole group and those who scored above. In this way, we obtained 67 participants with restricted orientation (age $M=23.70, S D=2.57$ ) and 61 participants with unrestricted orientation (age $M=23.16, S D=2.37$ ). In the first group, the mean SOI-R score was $20.63(S D=6.29)$, and in the second group it was $43.80(S D=7.02)$. The two groups did not differ in age, $U=1018.00, p>.50$ or height, $t=-.50, p<.70$, and other demographic variables (place of living, education); therefore these factors were not included in the analysis.

\section{Attractiveness Ratings: Size and Profile}

There was a significant main effect of breast size on attractiveness rating across all 15 images, $F(2.5,2598.6)=90.03$, $p<.001$ (with Greenhouse-Geisser correction). The C size ( $M=$ $6.57, S D=.10)$ and $\mathrm{D}$ size $(M=6.10, S D=.13)$ were rated as the most attractive and the A size was rated the least attractive $(M=3.84, S D=.11)$. There was also a significant main effect of the presented breast profile on attractiveness rating across all 15 images, $F(2,260)=4.88, p<.01$. Contrasts revealed that the difference was significant for the oblique view and the side view. Attractiveness of breasts presented in oblique view were rated generally higher than in side view, $F(1,130)=9.99 p<.01$. There was no significant difference in attractiveness rating between front and oblique view, $F(1,130)=1.54, p<.30$ and between front and side view, $p<.80$. The interaction between breast size and profile was significant, $F(6.05,785.88)=21.76$, $p<.001$ (with Greenhouse-Geisser correction). A and B sizes were rated as more attractive when presented in oblique and side view whereas $D$ and $E$ sizes were rated as more attractive when presented in front view. The $\mathrm{C}$ size was rated similarly across all three profiles.

\section{Attractiveness Ratings: Size $\times$ Profile $\times$ SOI-R}

The breast size $\times$ profile $\times$ male sociosexuality interaction on attractiveness rating was significant, $F(8,1008)=2.37, p<.02$.
This showed that profile and size interaction influenced attractiveness rating assessed as a function of SOI-R classification. We tested separately the impact of breast size and profile on breast attractiveness ratings by sociosexually restricted and unrestricted men. There was a significant interaction effect between the size and attractiveness rating and SOI-R score of participants, $F(2.53,318.32)=95.52, p<.001$ (with Greenhouse-Geisser correction). Sociosexually restricted and unrestricted men rated similarly small sizes but sociosexually unrestricted men rated $\mathrm{D}$ and $\mathrm{E}$ size higher that restricted men $(M=6.67, \mathrm{SD}=.18$ and $M=5.63, \mathrm{SD}=.17$ respectively for $\mathrm{D}$ size, and $M=5.72, \mathrm{SD}=.19$ and $M=4.16, \mathrm{SD}=.19$ respectively for $\mathrm{E}$ size). In both groups, the attractiveness rating was increasing up to D size and decreased for E size (see Fig. 1). Since there was no significant interaction between attractiveness rating and profile depending on rater's sociosexuality, $F(1$, $126)=.05, p>.09$, we analyzed the influence of male sociosexuality on breast attractiveness rating separately for all three profiles.

In each profile, there was a significant interaction between breast size attractiveness ratings and SOI-R, $F(3.12,329.81)=$ 4.40 for front view, $F(2.32,292.32)=7.36$ for oblique view, and $F(3.13,395.02)=5.21$ (all significant at $p<.05$ level; with Greenhouse-Geisser correction) for side view. This means that attractiveness ratings of different breast size varied in sociosexually restricted and unrestricted men for each profile. Although generally unrestricted men tended to give higher ratings than restricted ones, the former give significantly higher ratings only for the largest $\mathrm{E}$ size in the front view and, for $\mathrm{D}$ and $\mathrm{E}$ sizes, in oblique and side view (see Fig. 1).

\section{Discussion}

Large breasts received higher attractiveness ratings from men who scored high on the SOI-R than from men who scored relatively low. This means that men who tend to engage in shortterm, low-commitment relationships (unrestricted men) are more attracted to large breast sizes than men who tend to engage in longterm relationships with high emotional commitment (restricted men) (Simpson \& Gangestad, 1991).

Our results were analogous with those obtained by Swami et al. (2008) for WHR and BMI. In their study, unrestricted men rated females with low BMI and low WHR significantly more attractive than restricted men did, but both groups did not radically differ in their preferences. In our study, both restricted and unrestricted men rated sizes $\mathrm{C}$ and $\mathrm{D}$ the most attractive and the smallest sizes the least attractive, regardless of the viewing angle. Large sizes, however, were rated higher by unrestricted than restricted men.

These results suggest that male sociosexual orientation is an important mediating factor in perceptions of female 
attractiveness and plays a role in dynamic, context -dependent mate choice. Previous studies (Gangestad, 1993; Li \& Kenrick, 2006) have shown that unrestricted men rated physical attractiveness, which is assumed to be a reliable signal of mate quality, higher than personal/parenting qualities. The reverse was true for restricted individuals, who may prioritize traits other than physical attractiveness, i.e., interpersonal responsiveness and fidelity (Buss \& Schmitt, 1993; Provost et al., 2008; Simpson \& Gangestad, 1992).

The possible explanation for the difference between shortand long-term men would be related to the impact of a man's self-attractiveness and self-perceived value (Jones et al., 2005; Little et al., 2001) on a female attractiveness assessment (Brase $\&$ Walker, 2004). It is adaptive to shift preferences depending on one's own mate value and opportunities (Penke \& Denissen, 2008), and adjust the preferences to one's own attractiveness. However, in our study, we did not find a difference between restricted and unrestricted men in terms of height, one of the most important traits in male physical attractiveness (Hensley, 1994; Pierce, 1996; Salska et al., 2008); therefore, we think that this explanation of our results is rather unlikely.

There are a few reasons why large female breasts should be perceived as attractive. Large, developed, nulliparous breasts may signal female sexual maturity and fecundity to men (Sugiyama, 2005). It has been shown that women with low WHR and large breasts have higher mean and mid-cycle estradiol levels than other women. Also, regardless of WHR, estradiol level is higher in women with larger breasts than in women with smaller ones (Jasienska et al., 2004). Large breasts may also be a cue for better genetic quality. Due to possible instabilities at different stages of development, large breasts are more likely to be nonsymmetrical than small ones. Since low fluctuating asymmetry is a sign of good genotype, there may be a preference for large, symmetrical breasts versus asymmetrical ones (Manning et al., 1997; Moller, Soler, \& Thornhill, 1995). The other argument is that, in some body mass range, breast size positively correlates with overall body mass (Katch et al., 1980), which seems to be a better predictor of judgments of attractiveness than WHR (Swami \& Tovee, 2005) and strongly correlates with fertility (Frisch, 1988; Lake, Power, \& Cole, 1997). As we pointed out earlier, unrestricted men should be primarily interested in female fertility; therefore, they should be more prone to choose large breasts as the most attractive ones.

This was not, however, exactly the case in our study. Although the largest size E was significantly more attractive to the unrestricted than restricted men, the most attractive sizes for the unrestricted men were C and D. As breast size increases during pregnancy and lactation, there is a possibility that breasts that are too large signal that a woman is not fertile at the moment and, therefore, less attractive, especially for short-term mates. There is also a possibility that large breast sizes were rated as less attractive as they indicated more advanced age of a woman. In cultures where clothing conceals breast shape, the size may have become the determining factor of female age. However, previous studies showed that unrestricted men slightly discriminated young women (Young, Critelli, \& Keith, 2005); therefore, if age was the main reason, the E size should not have been rated as less attractive by sociosexually unrestricted men. Possibly, the size E was excessively large and thus not as attractive as the more "natural" (and common) but still large D size.

Restricted men may also discriminate against the largest size due to anticipated infidelity. Previous research has shown that females with large breasts are perceived as being more promiscuous and more sexually open than females with smaller breasts (Furnham et al., 1998; Millstred \& Frith, 2003; Tantleff-Dunn, 2002). Females with smaller breasts are perceived not only as moral and modest but also as competent, ambitious, and intelligent. Women with large breasts are attributed the opposite character traits (Kleinke \& Staneski, 1980) and, therefore, such women may be perceived as less attractive to restricted men.

We also obtained two other interesting results that may help in further research on female breast attractiveness. First, we found that men generally considered medium to large, but not extralarge, sizes to be the most attractive, thus confirming some results from previous studies (Gueguen, 2007a, b; Horvath, 1981) but not others (e.g., Furnham \& Swami, 2007; Singh \& Young, 1995). Beside the context-dependent mating preference, there may be a few reasons for this inconsistency. Most of the studies used as stimuli only two different breast sizes (small vs. large) (Furnham et al., 1998, 2006; Singh \& Young, 1995; Swami et al., 2009), thus showing that large breasts are more attractive than small ones. By using a 5-level scale, we found the most attractive size to be large but not extra-large. The inconsistency among these studies may be also caused by the use of different stimuli (photographs vs. line-drawing) and different viewing angles (front view vs. side view) (Furnham \& Swami, 2007). For instance, Furnham and Swami found that men preferred small breasts to large ones, when presented in side view and suggested that this result was due to the viewing angle. They showed the Females' figures in side view and not in front or oblique view as in the previous studies (e.g., Furnham et al., 2006; Singh, 1995). Second, we found that viewing angle changed rating of female attractiveness but we failed to show that small breasts were rated as more attractive when presented in side view.

In summary, our results suggest that male mating strategy, measured by sociosexual orientation, is an important mediating factor of perceived attractiveness of female breast size, and that physically attractive women are more valued by sociosexually unrestricted men. Furthermore, we found that medium to large breasts were the most attractive sizes for men and that the viewing angle may influence the attractiveness rating. This study also adds further dimensions to the literature on female body shape by examining breast size attractiveness, which is said to be neglected in the literature (Furnham \& Swami, 2007; Lynn, 2009). 
Acknowledgment We would like to thank Peter Frost for all valuable suggestions.

Open Access This article is distributed under the terms of the Creative Commons Attribution Noncommercial License which permits any noncommercial use, distribution, and reproduction in any medium, provided the original author(s) and source are credited.

\section{References}

Anderson, J., Crawford, C., Nadeau, J., \& Lindberg, T. (1992). Was the Dutchess of Windsor right? A cross-cultural review of the socioecology of ideals of female body shape. Ethology and Sociobiology, 13, 197-227.

Barber, N. (1995). The evolutionary psychology of physical attractiveness: Sexual selection and human morphology. Ethology and Sociobiology, $16,395-424$

Brase, G., \& Walker, G. (2004). Male sexual strategies modify ratings of female models with specific waist-to-hip ratios. Human Nature, 15 , 209-224.

Buss, D. (1989). Sex differences in human mate preferences: Evolutionary hypotheses tested in 37 cultures. Behavioral and Brain Sciences, 12, 1-49.

Buss, D., \& Schmitt, D. (1993). Sexual strategies theory: an evolutionary perspective on human mating. Psychological Review, 100, 204-232.

Dixson, B. J., Vasey, P. L., Sagata, K., Sibanda, N., Linklater, W. L., \& Dixson, A. F. (2010). Men's preferences for women's breast morphology in New Zealand, Samoa, and Papua New Guinea. Archives of Sexual Behavior, doi:10.1007/s10508-010-9680-6.

Frisch, R. (1988). Fatness and fertility. Scientific American, 258, 88-95.

Furnham, A., Dias, M., \& McClelland, A. (1998). The role of body weight, waist-to-hip ratio, and breast size in judgments of female attractiveness. Sex Roles, 39, 311-326.

Furnham, A., \& Swami, V. (2007). Perceptions of female buttocks and breast size in profile. Social Behavior and Personality, 35, 1-8.

Furnham, A., Swami, V., \& Shah, K. (2006). Body weight, waist-to-hip ratio and breast size correlates of ratings of attractiveness and health. Personality and Individual Differences, 41, 443-454.

Gangestad, S. (1993). Sexual selection and physical attractiveness: Implications for mating dynamics. Human Nature, 4, 205-235.

Gangestad, S., \& Simpson, J. (2000). The evolution of human mating: Trade-offs and strategic pluralism. Behavioral and Brain Sciences, 23, 573-644.

Gueguen, N. (2007a). Women's bust size and men's courtship solicitation. Body Image, 4, 386-390.

Gueguen, N. (2007b). Bust size and hitchhiking: A field study. Perceptual and Motor Skills, 105, 1294-1298.

Henderson, J., \& Anglin, J. (2003). Facial attractiveness predicts longevity. Evolution and Human Behavior, 24, 351-356.

Hensley, W. E. (1994). Height as a basis for interpersonal attraction. Adolescence, 29, 469-474.

Horvath, T. (1981). Physical attractiveness: The influence of selected torso parameters. Archives of Sexual Behavior, 10, 21-24.

Jasienska, G., Lipson, S., Ellison, P., Thune, I., \& Ziomkiewicz, A. (2006). Symmetrical women hale higher potential fertility. Evolution and Human Behavior, 27, 390-400.

Jasienska, G., Ziomkiewicz, A., Ellison, P., Lipson, S., \& Thune, I. (2004). Large breasts and narrow waists indicate high reproductive potential in women. Proceedings of the Royal Society London B, 271, 12131217.

Jones, D. (1996). An evolutionary perspective on physical attractiveness. Evolutionary Anthropology, 5, 97-109.
Jones, B., Little, A., Boothroyd, L., Feinberg, D., Cornwell, E., De Bruine, L., et al. (2005). Women's physical and psychological conditions independently predict their preference for apparent health in faces. Evolution and Human Behavior, 26, 451-457.

Katch, V., Campaingne, B., Freedson, P., Sady, S., Katch, F., \& Behnke, A. (1980). Contribution of breast volume and weight to body fat distribution in females. American Journal of Physical Anthropology, 53, 93-100.

Kenrick, D., Sadalla, E., Groth, G., \& Trost, M. (1990). Evolution, traits, and the stages of human courtship: Qualifying the parental investment model. Journal of Personality, 58, 97-116.

Kleinke, C., \& Staneski, R. (1980). First impressions of female bust size. Journal of Social Psychology, 110, 123-134.

Lake, J., Power, C., \& Cole, T. (1997). Women's reproductive health: The role of body mass index in early and adult life. International Journal of Obesity, 21, 432-438.

Li, N., \& Kenrick, D. (2006). Sex similarities and differences in preferences for short-term mates: What, whether, and why. Journal of Personality and Social Psychology, 90, 468-489.

Little, A., Burt, D., Penton-Voak, S., \& Perrett, D. (2001). Self-perceived attractiveness influences human female preferences for sexual dimorphism and symmetry in male faces. Proceedings of the Royal Society London B, 268, 39-44.

Lynn, M. (2009). Determinants and consequences of female attractiveness and sexiness: Realistic test with restaurant waitress. Archives of Sexual Behavior, 38, 737-745.

Manning, J., Scutt, D., Whitehouse, G., \& Leinster, S. (1997). Breast asymmetry and phenotypic quality in women. Evolution and Human Behavior, 18, 223-236.

Millsted, R., \& Frith, H. (2003). Being large breasted: Women negotiating embodiment. Women's Studies International Forum, 26, 455465.

Moller, A., Soler, M., \& Thornhill, R. (1995). Breast asymmetry, sexual selection, and human reproductive success. Ethology and Sociobiology, 16, 207-219.

Pawlowski, B., \& Jasienska, G. (2008). Women's body morphology and preferences for sexual partners' characteristics. Evolution and Human Behavior, 29, 19-25.

Penke, L., \& Asendorpf, J. (2008). Beyond global sociosexual orientations: A more differentiated look at sociosexuality and its effects on courtship and romantic relationships. Journal of Personality and Social Psychology, 95, 1113-1135.

Penke, L., \& Denissen, J. (2008). Sex differences and lifestyledependent shifts in the attunement of self-esteem to self-perceived mate value: Hints to an adaptive mechanism? Journal of Research in Personality, 42, 1123-1129.

Pierce, C. A. (1996). Body height and romantic attraction: A metaanalytic test of the male-taller norm. Social Behavior and Personality, 24, 143-149.

Provost, M., Troje, N., \& Quinsey, V. (2008). Short-term mating strategies and attraction to masculinity in point-light walkers. Evolution and Human Behavior, 29, 65-69.

Regan, P. (1998). What if you can't get what you want? Willingness to compromise ideal mate selection standards as a function of sex, mate value, and relationship context. Personality and Social Psychology Bulletin, 24, 1288-1297.

Sacco, D., Hugenberg, K., \& Sefeck, J. (2009). Sociosexuality and face perception: Unrestricted sexual orientation facilitates sensitivity to female facial cues. Personality and Individual Differences, 47, $777-782$.

Salska, I., Frederick, D. A., Pawlowski, B., Reilly, A. H., Laird, K. T., \& Rudd, N. A. (2008). Conditional mate preferences: Factors influencing preferences for height. Personality and Individual Differences, 44, 203-215. 
Scheib, J., Gangestad, S., \& Thornhill, R. (1999). Facial attractiveness, symmetry and cues of good genes. Proceedings of the Royal Society London B, 266, 1913-1917.

Shackelford, T., \& Larsen, R. (1999). Facial attractiveness and physical health. Evolution and Human Behavior, 20, 71-76.

Simpson, J., \& Gangestad, S. (1991). Individual differences in sociosexuality: Evidence for convergent and discriminant validity. Journal of Personality and Social Psychology, 60, 870-883.

Simpson, J., \& Gangestad, S. (1992). Sociosexuality and romantic partner choice. Journal of Personality, 60, 31-51.

Singh, D. (1993). Adaptive significance of female physical attractiveness: Role of waist-to-hip ratio. Journal of Personality and Social Psychology, 65, 293-307.

Singh, D. (1995). Female health, attractiveness and desirability for relationships: Role of breast asymmetry and waist-to-hip ratio. Ethology and Sociobiology, 16, 465-481.

Singh, D., \& Young, R. (1995). Body weight, waist-to-hip ratio, breasts, and hips: Role in judgments of female attractiveness and desirability for relationships. Ethology and Sociobiology, 16, 483-507.

Sugiyama, L. S. (2005). Physical attractiveness in adaptationist perspective. In D. M. Buss (Ed.), The handbook of evolutionary psychology (pp. 292-343). Hoboken, NJ: Wiley.

Swami, V., Jones, J., Einon, D., \& Furnham, A. (2009). Men's preferences for women's profile waist-to-hip ratio, breast size, and ethnic group in Britain and South Africa. British Journal of Psychology, 100, $313-325$

Swami, V., Miller, R., Furnham, A., Penke, L., \& Tovee, M. (2008). The influence of men's sexual strategies on perceptions of women's bodily attractiveness, health and fertility. Personality and Individual Differences, 44, 98-107.
Swami, V., \& Tovee, M. (2005). Female physical attractiveness in Britain and Malaysia: A cross-cultural study. Body Image, 2, 115-128.

Symons, D. (1979). The evolution of human sexuality. New York: Oxford University Press.

Tantleff-Dunn, S. (2002). Biggest isn't always best: The effect of breast size on perception of women. Journal of Applied Social Psychology, 32, 2253-2265.

Thornhill, R., \& Gangestad, S. (1999). Human facial beauty, averageness, symmetry, and parasite resistance. Human Nature, 4, 237 269.

Thornhill, R., \& Grammer, K. (1999). The body and face of women: One ornament that signals quality? Evolution and Human Behavior, 20, $105-120$.

Tovee, M., \& Cornelissen, P. (2001). Female and male perceptions of female physical attractiveness in front-view and profile. British Journal of Psychology, 92, 391-402.

Tovee, M., Maisey, D., Emery, J., \& Cornelissen, P. (1999). Visual cues to female physical attractiveness. Proceedings of the Royal Society London B, 266, 211-218.

Waynforth, D., \& Dunbar, R. (1995). Conditional mate choice strategies in humans: Evidence from "Lonely Heart's advertisements". Behavior, $132,755-779$.

Wetsman, A., \& Marlowe, F. (1999). How universal are preferences for female wait-to-hip ratios? Evidence from Hadza of Tanzania. Evolution and Human Behavior, 20, 219-228.

Young, J., Critelli, J., \& Keith, K. (2005). Male age preferences for shortterm and long-term mating. Sexualities, Evolution and Gender, 7, 8393. 